\title{
The Scientific Revolution in Power Plants
}

\section{Mohamed Hyder Seid-Ahmed Elfaki}

Abu Halima (Block 1, No. 303), Khartoum, Sudan

Email: energy_of_nature@hotmail.com

Received October 21 ${ }^{\text {st }}, 2011$; revised March 26 ${ }^{\text {th }}, 2012$; accepted April $3^{\text {rd }}, 2012$

\begin{abstract}
It has been made a proposal of new ideal cycle for power plants which is working by a turbine gas, for both closed and open systems. It has been designed a special device for adding heat at constant volume. The aim of special device is to decrease the amount of added heat for the new cycle. We have made a comparison between the simple gas turbine cycle $\&$ the new cycle. The results has been shown, that the efficiency of new cycle is greater than the simple cycle of gas turbine.
\end{abstract}

Keywords: I,C (Internal Combustion); E.C (External Combustion); S.C (Simple Gas Turbine Cycle); N.C (New Cycle)

\section{Introduction}

The research is concerning with a branch of mechanical engineering which is called thermodynamic. It is always has a relation with producing energy either for electricity generation, cars, planes and trains by using the thermal energy. The increasing of the thermal efficiency has been considered as important parameter for mechanical engineers who they want to specialize in the thermodynamic science and power plants. They usually want to reach the maximum efficiency as possible because they know the effects of increasing of the thermal efficiency all over the world in economical, environmental and development sides.

\section{The New Ideal Cycle for Internal Combustion Power Plants}

\subsection{The Parts of New Ideal Cycle}

The Figure 1 represents the $(\mathrm{P}-\mathrm{V})$ diagram of the new ideal cycle for internal combustion power plants and Figure 2 represents the components of the new ideal cycle.

We see that the new ideal cycle has only 4 processes:

- Process (1-2): adding heat at constant volume by using special device.

- Process (2-3): adding heat at constant pressure by using the injection of fuel.

- Process (3-4): isentropic expansion by using turbine.

- Process (4-5): rejecting heat at constant pressure by using the special device.

\subsection{Analysis of New Ideal Cycle}

We know that the pressure at state 2 in Figure 1 is:

$$
P_{2}=P_{1}\left(\frac{T_{2}}{T_{1}}\right)
$$
is:

Because $V_{1}=V_{2}$ so, the inlet temperature of turbine

$$
T_{3}=T_{4}\left(\frac{P_{2}}{P_{4}}\right)^{\frac{K-1}{K}}
$$
tain:

By substituting Equation (1) in Equation (2) we ob-

$$
T_{3}=T_{4}\left(\frac{P_{1} T_{2}}{P_{4} T_{1}}\right)^{\frac{K-1}{K}}
$$

The thermal equilibrium between process (1-2) \& (4-5) is given by:

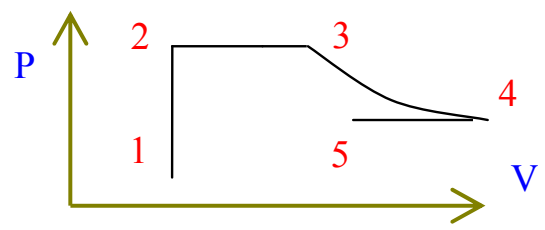

Figure 1. The (P-V) diagram of the I.C cycle.

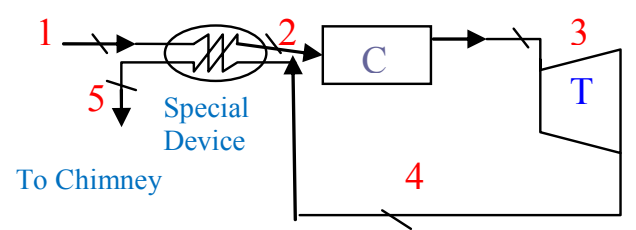

Figure 2. Components of the I.C cycle. 


$$
\begin{gathered}
\dot{Q}_{1-2}=\dot{Q}_{4-5} \\
\dot{m}_{1-2} C_{V_{\text {air }}}\left[T_{2}-T_{1}\right]=\dot{m}_{4-5} C_{P_{\text {exh }}}\left[T_{4}-T_{5}\right]
\end{gathered}
$$

We assume that $\left(\dot{m}_{1-2}=\dot{m}_{4-5}\right)$, then:

$$
C_{V_{\text {air }}}\left[T_{2}-T_{1}\right]=C_{P_{\text {exh }}}\left[T_{4}-T_{5}\right]
$$

We solve Equation (6) for $T_{4}$, so we obtain:

$$
T_{4}=\frac{C_{V_{\text {air }}}}{C_{P_{\text {exh }}}}\left[T_{2}-T_{1}\right]+T_{5}
$$

The specific work of special device is:

$$
W_{S . D}=R_{\text {air }}\left[T_{2}-T_{1}\right]
$$

The specific work of turbine is given by:

$$
W_{t}=C_{P_{\text {exh }}}\left[T_{3}-T_{4}\right]
$$

We substitute Equation (3) in Equation (8), so we have:

$$
W_{t}=C_{P_{e x h}} T_{4}\left[\left(\frac{P_{1} T_{2}}{P_{4} T_{1}}\right)^{\frac{K-1}{K}}-1\right]
$$

The specific heat added in the cycle is given by:

$$
Q_{a}=C_{P_{\text {exh }}}\left[T_{3}-T_{2}\right]
$$

Also, we substitute Equation (3) in Equation (10), and then we have:

$$
Q_{a}=C_{p_{e x h}}\left[T_{4}\left(\frac{P_{1} T_{2}}{P_{4} T_{1}}\right)^{\frac{K-1}{K}}-T_{2}\right]
$$

The thermal efficiency is given by:

$$
\eta_{t h}=\frac{W_{t}-W_{S . D}}{Q_{A}}
$$

We substitute Equation (9), (10) \& (12) in equation (13), and then we will have:

$$
\eta_{t h}=\frac{C_{P_{e x h}} T_{4}\left[\left(\frac{P_{1} T_{2}}{P_{4} T_{1}}\right)^{\frac{K-1}{K}}-1\right]-R_{\text {air }}\left(T_{2}-T_{1}\right)}{C_{P_{e x h}}\left(T_{4}\left(\frac{P_{1} T_{2}}{P_{4} T_{1}}\right)^{\frac{K-1}{K}}-T_{2}\right)}
$$

Notice:

- In this new ideal cycle, it must be $T_{2} \leq T_{4}$, and when we assume that the effectiveness of exchanger is $100 \%, T_{2}=T_{4}$.

- The temperature at state 5 must be the minimum temperature of gas exhaust $T_{5}=473 \mathrm{~K}$, to avoid the condensation of corrosive gases in the pipe.

\section{Example (1-1):}

- Data:

$T_{1}=300 \mathrm{~K}, T_{3}=1150 \mathrm{~K}, r_{p}=3, P_{1}=1$ bar $P_{4}=1.1$ bar, $C_{V_{\text {air }}}=0.718 \mathrm{KJ} / \mathrm{Kg}, C_{P_{\text {exh }}}=1.11 \mathrm{KJ} / \mathrm{Kg}, C_{P_{\text {air }}}=$ $1.005 \mathrm{KJ} / \mathrm{Kg}, \quad K_{\text {air }}=1.4, \quad K_{\text {gas }}=1.3$

- Find:

$\eta_{\text {th }}$ for new cycle \& S.G.T.C, $\eta_{\text {Carnot }}$

- Solution:

1) New cycle:

$$
T_{2}=r_{p} * T_{1}=3 * 300=900 \mathrm{~K}
$$

$$
\begin{gathered}
T_{4}=\frac{T_{3}}{\left(r_{p} / P_{4}\right)^{\left(\frac{K-1}{K}\right)}}=\frac{1150}{(3 / 1.1)^{\left(\frac{1.3-1}{0.3}\right)}}=912.3 K_{5} \\
T_{5}=T_{4}-\frac{C_{V_{\text {air }}}}{C_{P_{\text {exh }}}}\left(T_{2}-T_{1}\right)=912.3-\frac{0.718}{1.11}(900-300) \\
=524.2 \mathrm{~K}(\text { Safe }-\mathrm{Temp} .) \\
W_{S . D}=R_{\text {air }}\left[T_{2}-T_{1}\right]=0.287 *(900-300)=172.2 \mathrm{KJ} / \mathrm{Kg} \\
W_{t}=C_{p_{\text {exh }}}\left[T_{3}-T_{4}\right]=1.11 *(1150-912.3)=263.8 \mathrm{KJ} / \mathrm{Kg} \\
Q_{a}=C_{p_{\text {exh }}}\left[T_{3}-T_{2}\right]=1.11 *(1150-900)=277.5 \mathrm{KJ} / \mathrm{Kg} \\
\eta_{\text {th }}=\frac{W_{t}-W_{S . D}}{Q_{A}}=\frac{263.8-172.2}{277.3}=33 \% \\
\eta_{\text {carnot }}=1-\frac{T_{L}}{T_{H}}=1-\frac{300}{1150}=73.91 \%
\end{gathered}
$$

2) S.C (Open System):

$$
\begin{aligned}
T_{2} & =T_{3}\left(r_{p}\right)^{\frac{\gamma-1}{\gamma}}=1150 * 3^{\left(\frac{1.4-1}{1.4}\right)}=410.6 \mathrm{~K} \\
\eta_{t h} & =\frac{W_{t}-W_{\text {Comp }}}{Q_{A}}=\frac{C_{P_{\text {exh }}}\left(T_{3}-T_{2}\right)-C_{P_{\text {air }}}\left(T_{2}-T_{1}\right)}{C_{P_{\text {exh }}}\left(T_{3}-T_{2}\right)} \\
& =\frac{1.11 *(1150-912.3)-1.005 *(410.6-300)}{1.11 *(1150-410.6)} \\
& =18.6 \%
\end{aligned}
$$

It seems that the efficiency of new cycle is greater than the simple cycle of gas turbine.

The Table 1 indicates the difference value of $r_{p} \&$ $T_{3}$ to obtain other temperature, specific work of special device \& turbine, amount of added heat, work ratio, efficiency of cycle and Carnot efficiency between the new cycle (N.C) \& S.C (Open System).

In the aircraft practice where the life expectancy of the engine is shorter, the maximum temperature used are usually higher than those used in industrial and marine gas turbine units, more expensive alloys and blade cooling allow maximum temperature of above $1600 \mathrm{~K}$ [1]. 
Table 1. Comparison between the new cycle \& S.G.T.C (Open System).

\begin{tabular}{ccccccc}
\hline & S.C & N.C & S. C & N.C & S. C & N.C \\
\hline$T_{1}$ & 300 & 300 & 300 & 300 & 300 & 300 \\
$T_{2}$ & 411 & 900 & 429 & 1050 & 437 & 1119 \\
$T_{3}$ & 1200 & 1200 & 1400 & 1400 & 1500 & 1500 \\
$T_{4}$ & 942 & 942 & 1060 & 1060 & 1120 & 1120 \\
$T_{5}$ & N.A & 554 & N.A & 575 & N.A & 590 \\
$P_{1}$ & 1 & 1 & 1 & 1 & 1 & 1 \\
$P_{4}$ & 1.05 & 1.05 & 1.05 & 1.05 & 1.05 & 1.05 \\
$r_{p}$ & 3 & 3 & 3.5 & 3.5 & 3.73 & 3.73 \\
$W_{\text {comp }}$ & 111 & N.A & 130 & N.A & 138 & N.A \\
$W_{S . D}$ & N.A & 172 & N.A & 215 & N.A & 253 \\
$W_{t}$ & 287 & 287 & 377 & 377 & 423 & 423 \\
$Q_{a}$ & 876 & 333 & 1078 & 389 & 1180 & 423 \\
$W_{\text {net }}$ & 175 & 114 & 247 & 162 & 285 & 187 \\
work & 61.2 & 39.9 & 65.6 & 42.9 & 67.4 & 44.3 \\
ratio & & & & & & \\
$\eta_{\text {th }}$ & 20.0 & 34.3 & 22.9 & 41.6 & 24.1 & 44.3 \\
$\eta_{\text {Carnot }}$ & 75 & 75 & 78.6 & 78.6 & 80 & 80 \\
\hline
\end{tabular}

\section{The New Ideal Cycle for External Combustion Power Plants}

\subsection{The Parts of New Ideal Cycle}

The Figure 3 represents the $(\mathrm{P}-\mathrm{V})$ diagram of the new ideal cycle for external combustion power plants and Figure 4 represents the components of the new ideal cycle.

We see that the new ideal cycle has only 5 processes:

- Process (1-2): adding heat at constant volume by using the special device.

- Process (2-3): adding heat at constant pressure by using exchanger.

- Process (3-4): isentropic expansion by using turbine.

- Process (4-5): rejecting heat at constant pressure by using the special device.

- Process (5-1): rejecting heat at constant pressure by using exchanger which the working substance can be water, air etc.

\subsection{Analysis of New Ideal Cycle}

We know that the pressure at state 2 in Figure $\mathbf{3}$ is:

$$
P_{2}=P_{1}\left(\frac{T_{2}}{T_{1}}\right)
$$

Because $V_{1}=V_{2}$ and $P_{1}=P_{4}$ so, the inlet temperature of turbine is:

$$
T_{3}=T_{4}\left(\frac{P_{2}}{P_{4}}\right)^{\frac{\gamma-1}{\gamma}}
$$

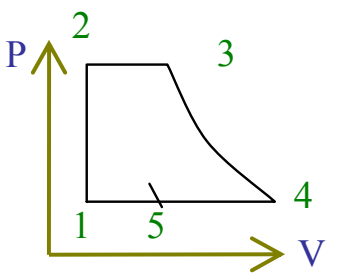

Figure 3. The (P-V) diagram of for E.C cycle.

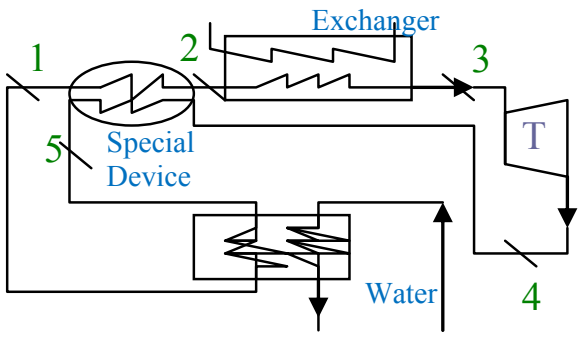

Figure 4. The components of the for E.C cycle.

By substituting Equation (15) in Equation (16) we obtain:

$$
T_{3}=T_{4}\left(\frac{T_{2}}{T_{1}}\right)^{\frac{\gamma-1}{\gamma}}
$$

The thermal equilibrium between process (1-2) \& (4-5) is given by:

$$
\begin{aligned}
& \dot{Q}_{1-2}=\dot{Q}_{4-5} \\
& \dot{m}_{1-2} C_{V}\left[T_{2}-T_{1}\right]=\dot{m}_{4-5} C_{p}\left[T_{4}-T_{5}\right]
\end{aligned}
$$

We assume that $\left(\dot{m}_{1-2}=\dot{m}_{4-5}\right)$, then:

$$
C_{V}\left[T_{2}-T_{1}\right]=C_{p}\left[T_{4}-T_{5}\right]
$$

We solve Equation (20) for $T_{5}$, so we obtain:

$$
T_{5}=T_{4}-\gamma^{-1}\left[T_{2}-T_{1}\right]
$$

The specific work of special device is:

$$
W_{S . D}=R_{\text {air }}\left[T_{2}-T_{1}\right]
$$

The specific work of turbine is given by:

$$
W_{t}=C_{P}\left[T_{3}-T_{4}\right]
$$

We substitute Equation (17) in Equation (23), so we have:

$$
W_{t}=C_{p} T_{4}\left[\left(\frac{T_{2}}{T_{1}}\right)^{\frac{\gamma-1}{\gamma}}-1\right]
$$

The specific heat added in the cycle is given by:

$$
Q_{a}=C_{p_{e x h}}\left[T_{3}-T_{2}\right]
$$

Also, we substitute Equation (17) in Equation (25), and then we have: 


$$
Q_{a}=C_{p}\left[T_{4}\left(\frac{T_{2}}{T_{1}}\right)^{\frac{\gamma-1}{\gamma}}-T_{2}\right]
$$

The thermal efficiency is given by:

$$
\eta_{t h}=\frac{W-W_{S . D}}{Q_{A}}
$$

We substitute Equation (22), (24) \& (26) in Equation (26), and then we have:

$$
\eta_{t h}=\frac{C_{P_{a i r}} T_{4}\left[\left(\frac{T_{2}}{T_{1}}\right)^{\frac{\gamma-1}{\gamma}}-1\right]-R\left(T_{2}-T_{1}\right)}{C_{P_{\text {air }}} T_{4}\left(\frac{T_{2}}{T_{1}}\right)^{\frac{\gamma-1}{\gamma}}-T_{2}}
$$

Example (2-1):

- Data: $T_{1}=300 \mathrm{~K}, T_{3}=1250 \mathrm{~K}, r_{p}=3, P_{1}=1$ bar $C_{V_{\text {air }}}=$ $0.718 \mathrm{KJ} / \mathrm{Kg}, \quad C_{P_{a i r}}=1.005 \mathrm{KJ} / \mathrm{Kg}, \quad K_{\text {air }}=1.4$,

- Find:

$\eta_{\text {th }}$ for new cycle \& S.G.T.C, $\eta_{\text {Carnot }}$

- Solution:

1) New cycle:

$$
\begin{gathered}
T_{2}=r_{p} * T_{1}=3 * 300=900 \mathrm{~K} \\
T_{4}=\frac{T_{3}}{\left(r_{p}\right)}=\frac{1250}{\left(\frac{\gamma-1}{\gamma}\right)}=913.2 K_{5}\left(\frac{1.4-1}{0.4}\right) \\
T_{5}=T_{4}-\frac{C_{V_{\text {air }}}}{C_{P_{\text {exh }}}}\left(T_{2}-T_{1}\right) \\
T_{5}=912.3-\frac{0.718}{1.005}\left(900-300_{1}\right)=482.8 \mathrm{~K} \\
W_{S . D}=R_{\text {air }}\left[T_{2}-T_{1}\right]=0.287 *(900-300)=172.2 \mathrm{KJ} / \mathrm{Kg} \\
W_{t}=C_{p_{\text {air }}}\left[T_{3}-T_{4}\right] \\
=1.005 *(1250-913.2)=338.5 \mathrm{KJ} / \mathrm{Kg} \\
Q_{a}=C_{p_{\text {air }}}\left[T_{3}-T_{2}\right]=1.005 *(1250-900)=351.7 \mathrm{KJ} / \mathrm{Kg} \\
\eta_{\text {th }}=\frac{W_{t}-W_{S . D}}{Q_{A}}=\frac{338.5-172.2}{351.7}=47.3 \% \\
\eta_{\text {carnot }}=1-\frac{T_{L}}{T_{H}}=1-\frac{300}{1250}=76 \%
\end{gathered}
$$

2) S.C (Closed System):

$$
\eta_{t h}=1-\frac{1}{\left(r_{p}\right)^{\frac{\gamma-1}{\gamma}}}=1-\frac{1}{3^{\left(\frac{1.4-1}{1.4}\right)}}=26.9 \%
$$

The Table 2 indicates the difference value of $r_{p} \&$ $T_{3}$ to obtain other temperature, specific work of special device \& turbine, amount of added heat, work ratio, efficiency of cycle and Carnot efficiency between the new cycle \& S.C (Closed System).

\section{The Special Device for Adding Heat at Constant Volume}

\subsection{Components of the Special Device}

As we see in Figure 5, the special device constitutes from 12 parts as follow:
1) Inlet pipe of air.
2) Outlet pipe of air.
3) Cam, which it is fixed.
4) Piston.
5) Exchanger-between air and exhaust gas.
6) Rotary part.
7) Exhaust gas outlet tube.

Table 2. Comparison between the new cycle \& S.C (Closed System).

\begin{tabular}{ccccccc}
\hline & S.C & N.C & S. C & N.C & S.C & N.C \\
\hline$T_{1}$ & 300 & 300 & 300 & 300 & 300 & 300 \\
$T_{2}$ & 390 & 750 & 411 & 900 & 429 & 1050 \\
$T_{3}$ & 1000 & 1000 & 1350 & 1350 & 1510 & 1510 \\
$T_{4}$ & 770 & 770 & 986 & 986 & 1056 & 1056 \\
$T_{5}$ & N.A & 448 & N.A & 558 & N.A & 520 \\
$P_{1}$ & 1 & 1 & 1 & 1 & 1 & 1 \\
$r_{p}$ & 2.5 & 2.5 & 3 & 3 & 3.5 & 3.5 \\
$W_{\text {comp }}$ & 90 & N.A & 111 & N.A & 130 & N.A \\
$W_{S . D}$ & N.A & 129 & N.A & 172 & N.A & 215 \\
$W_{t}$ & 231 & 231 & 366 & 366 & 457 & 457 \\
$Q_{a}$ & 613 & 251 & 944 & 452 & 1086 & 462 \\
$W_{\text {net }}$ & 141 & 102 & 690 & 193 & 327 & 241 \\
work & 61 & 44.2 & 69.6 & 52.9 & 71.6 & 52.9 \\
ratio & & & & & & \\
$\eta_{\text {th }}$ & 23 & 40.7 & 26.9 & 42.7 & 30.1 & 52.2 \\
$\eta_{\text {Carnot }}$ & 70 & 70 & 77.8 & 77.8 & 80.1 & 80.1 \\
\hline
\end{tabular}

N.A $=$ Not Available

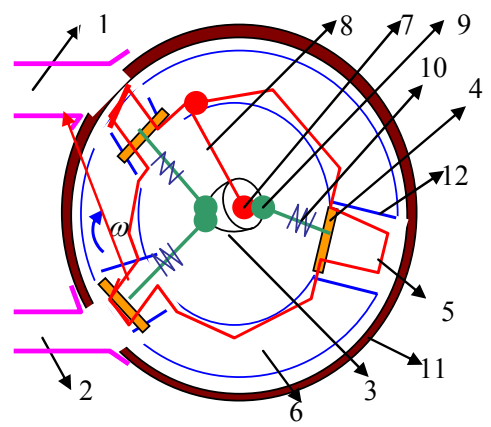

Figure 5. Components of the special device. 

8) Exhaust gas inlet tube.
9) Connection rod of piston.
10) Spring.
11) Fixed part.
12) Cylinder.

\subsection{The Working Mechanism of the Special Device}

- When the piston starts from the initial position, the vacuum of cylinder will be occupied by the air from the air inlet pipe as shown in Figure 6.

- After that, the temperature of air inside the cylinder will increase because there is an exchanger between a cool air and hot exhaust gas, see Figure 7.

- When the air reaches near the air outlet pipe, the all air inside the cylinder will be hot. Then the piston will compel the hot air to move outside the cylinder to the outlet pipe by using cam. See Figure 8.

- When the all air has been rejected from the cylinder, the above steps will be repeated for another new cool air.

\subsection{The Equations of the Special Device}

Before we start to find the equations, the special device which it is shown in Figure $\mathbf{5}$ has been modified to another kind, because the new kind is easy to study, but we must remember that the idea of the new kind is the same as we explained in previous subsection. The new kind is shown in Figure 9. The cam and air pipes are in front of and behind the page respectively.

\subsubsection{The Magnitude of the Force to Reject the Air from Cylinder}

As we know, the pressure inside the cylinder of air will increase as a result of arising in temperature, and the specific volume is constant then:

$$
f_{\text {air }}=P_{\max } A
$$

Also, we know that the area of cylinder is:

$$
A=\frac{\pi d^{2}}{4}
$$

By substituting Equation (30) in Equation (29), and then we have:

$$
f_{\text {air }}=P_{\max } * \frac{\pi d^{2}}{4}
$$

When the connection rod hit the cams as show in Figure 10, the analysis of forces will be if we neglect the force due to spring as shown in Figure 11, where " $F$ " is the force momentum of rotation of rotary part. " $R$ " is the reaction from the cam. " $f_{\text {air }}$ " is the force due to the air inside the cylinder.

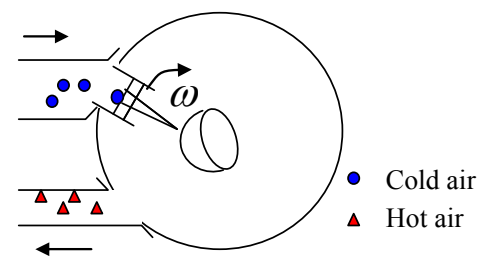

Figure 6. Cold air enters to the cylinder.

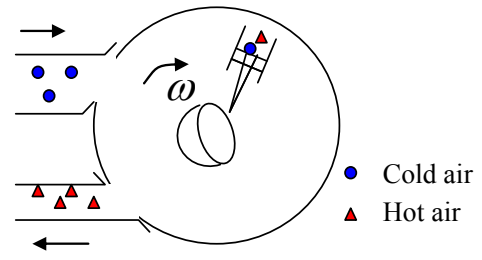

Figure 7. Increasing the temperature of air.

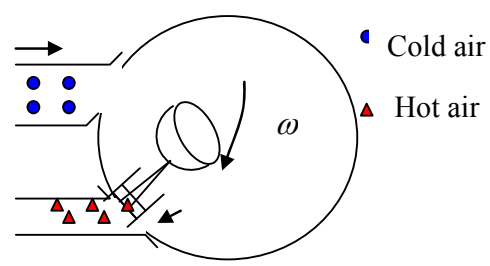

Figure 8. Rejecting the hot air from cylinder.

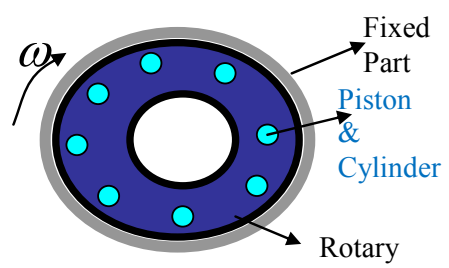

Figure 9. The new kind of the special device.

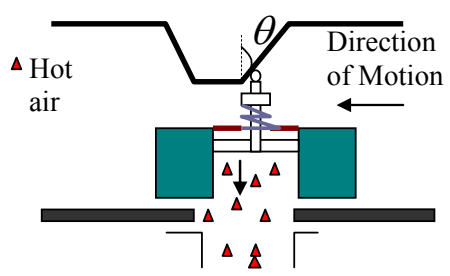

Figure 10. The process of rejecting the hot air.

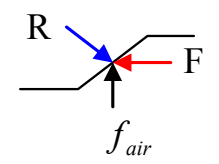

Figure 11. The free body diagram of forces on cam.

The analysis of the force:

In X-axis:

$$
\begin{aligned}
& F=R * \cos (\theta) \\
& R=\frac{F}{\cos (\theta)}
\end{aligned}
$$


In y-axis:

$$
f_{\text {air }}=R * \sin (\theta)
$$

By substituting Equation (33) in Equation (34) we obtain:

$$
f_{\text {air }}=R * \sin (\theta)
$$

Then, the minimum magnitude of the force to reject the air from the cylinder is:

$$
F_{\min }=\frac{f_{\text {air }}}{\tan (\theta)}
$$

\subsubsection{The Power of the Special Device}

We know that the torque of the circular motion can give by:

$$
\tau=I \alpha
$$

where $\tau, I$ and $\alpha$ are torque, momentum of inertia and Angular acceleration respectively.

The power of circular motion is given by:

$$
\tilde{P}=\tau * \omega
$$

where $\tilde{P}$ and $\omega$ are power and angular velocity respectively.

Also, we can express the torque as:

$$
\tau=F_{\min } * \bar{r}
$$

where " $\bar{r}$ " is the radius which it is reached from the center of the circle to the center of the piston.

By substituting Equation (39) in Equation (38) we obtain:

$$
\tilde{P}=F_{\min } * \bar{r} * \omega
$$

Now, we want to talk about an important parameter of Equation (38), it is the value of the angular velocity “ $\omega$ ".

As we see from Figure 12, the cylinder will move from it is initial position 1 to reach position 2 at angle of " $\phi$ " mafter a period of time " $t$ ", then:

$$
\omega=\frac{\phi^{r}}{t}
$$

" $t$ " will dependent on the time required to reach the air from initial to final temperature.

By substituting Equation (41) in Equation (40) we have:

$$
\tilde{P}=F_{\min } * \bar{r} * \frac{\phi^{r}}{t}
$$

Recall that:

$$
\phi^{r}=\frac{\pi}{180} \phi^{o}
$$

If, we substitute Equation (43) in Equation (42). Then, we have:

$$
\tilde{P}=\frac{\pi}{180} F_{\min } * \bar{r} * \frac{\phi^{o}}{t}
$$

Also, we can substitute Equations (36) \& (29) in Equation (42), and then we have:

$$
\tilde{P}=\frac{\pi}{180} \frac{P_{\max } A}{\tan (\theta)} * \bar{r} * \frac{\phi^{o}}{t}
$$

The last equation helps us to determine the power of special device.

Example (3-1):

- Data: $P_{\max }=2$ bar, $d=0.15 \mathrm{~m}, t=3 \mathrm{sec}, \bar{r}=$ $1.6 \mathrm{~m}, \phi=120^{\circ}, \theta=45^{\circ}$.

- Find: $A, \tilde{P}$.

- Solution:

$$
\begin{aligned}
A & =\frac{\pi d^{2}}{4}=\frac{\pi *(0.15)^{2}}{4}=0.01767 \mathrm{~m}^{2} \\
\tilde{P} & =\frac{\pi}{180} \frac{P_{\max } A}{\tan (\theta)} * \bar{r} * \frac{\phi^{\circ}}{t} \\
& =\frac{\pi * 2 \times 10^{5} * 0.01767 * 1.6 * 120}{180 * \tan (45) * 3} \\
& =3.95 \mathrm{Kw}
\end{aligned}
$$

The Table 3 indicates a different value of $P_{\max }, \theta \&$ $d$ to obtain the power of special device. The data for this table was given in the previous example.

We see from this table that the power of special device can be neglected, because it is too smaller than the work of turbine.

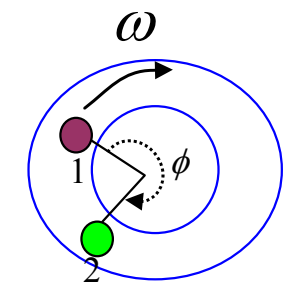

Figure 12. The angle $\phi$ of the cylinder.

Table 3. The power of special device.

\begin{tabular}{cccccccc}
\hline $\begin{array}{c}P_{\max } \\
\text { (bar) }\end{array}$ & $d(\mathrm{~m})$ & $\theta^{\circ}$ & $A\left(\mathrm{~m}^{2}\right)$ & $\bar{r}(m)$ & $\phi^{\circ}$ & $t(\mathrm{~s})$ & $\begin{array}{c}\tilde{P} \\
(\mathrm{Kw})\end{array}$ \\
\hline 3 & 0.15 & 45 & 0.017 & 1.6 & 120 & 3 & 5.92 \\
4 & 0.15 & 45 & 0.017 & 1.6 & 120 & 3 & 7.90 \\
4 & 0.2 & 45 & 0.031 & 1.6 & 120 & 3 & 14.0 \\
4 & 0.3 & 45 & 0.070 & 1.6 & 120 & 3 & 31.5 \\
4 & 0.3 & 60 & 0.070 & 1.6 & 120 & 3 & 18.2 \\
4 & 0.3 & 80 & 0.070 & 1.6 & 120 & 3 & 5.57 \\
\hline
\end{tabular}




\subsection{Concrete Method for Manufacturing the Special Device}

\subsubsection{Component of Special Device Separately}

The Figures 13-27 illustrate the major parts of the special device. Any one of these parts have a different function which is distinguished from other.

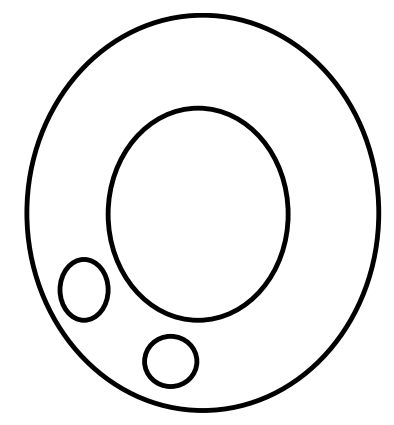

Figure 14. Fixed part No. 2.

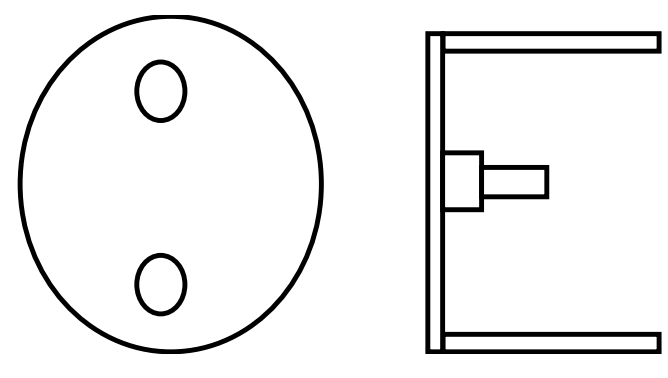

Figure 15. Piston No. 3.

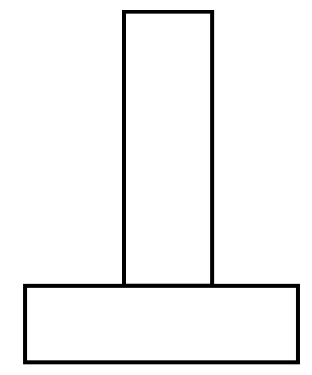

Figure 16. Connected column [2] for fixed part \& base (No. 4).

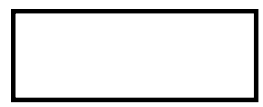

Figure 17. Tube No. 5.

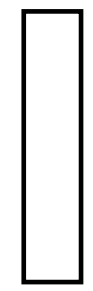

Figure 18. Connected column [1] for fixed part \& cams (No. 6).

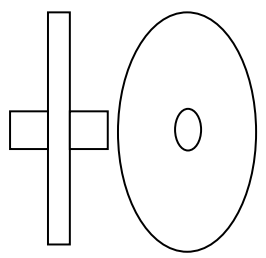

Figure 19. Rotary ring (No. 7).

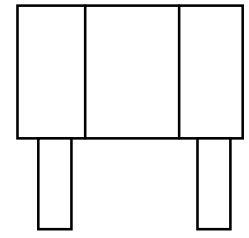

Figure 20. Base of special device (No. 8).

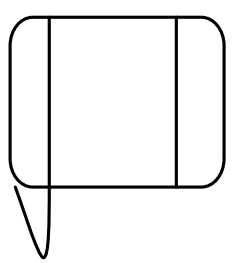

Figure 21. Cylinder with cams (No. 9).

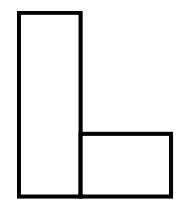

Figure 22. Pipe of inlet \& outlet air (No. 10).

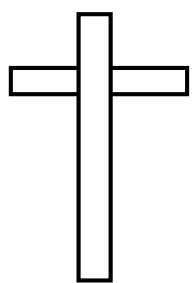

Figure 23. The column (No. 11).

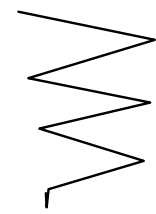

Figure 24. Spring (No. 12).

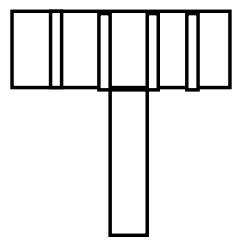

Figure 25. The gear (No. 13). 


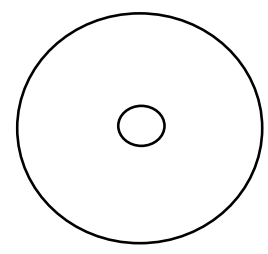

Figure 26. Ring (No. 14).

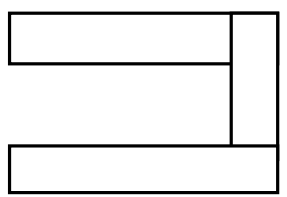

Figure 27. Exchanger (No. 15).

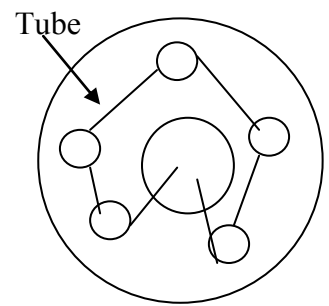

Figure 28. Rotary part with tubes.

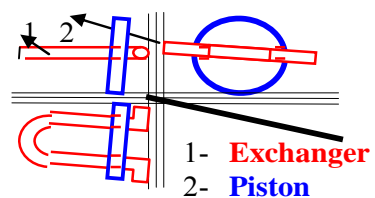

Figure 29. The projection of piston and exchanger.

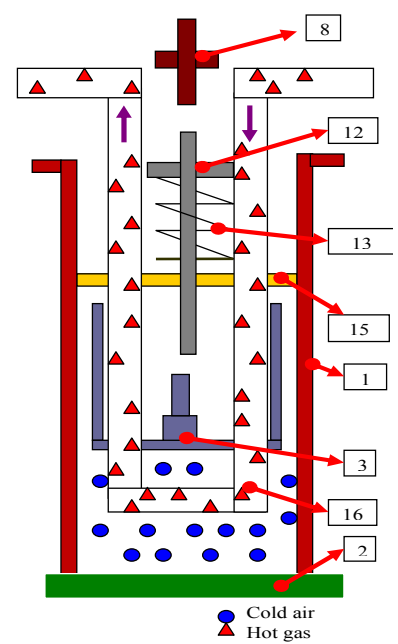

Figure 30. System of piston \& exchanger.

\subsubsection{Final Form of the Rotary Part with Tubes}

The rotary parts have many tubes which they are connected with each other as shows in Figure 28. These tubes contain the hot gases which come from exhaust gases of turbine.

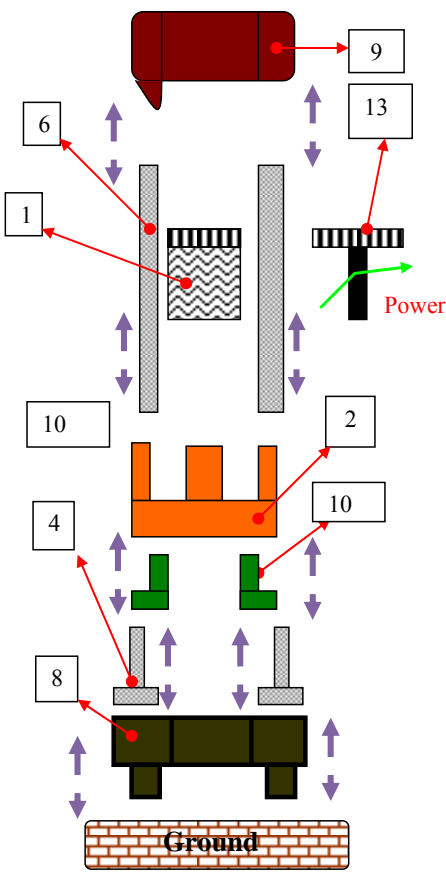

Figure 31. Arrangement of the special device.

\subsubsection{Final Form of the Piston \& Exchanger}

The shape of piston \& exchanger is very simple; we see in Figure 29 the projection of the piston \& exchanger. Figure 30 indicates how we can join the piston with rotary part to do the function of adding heat at constant volume.

\subsubsection{Arrangement the Components of the Special Device}

Figure 31 shows the method to arrange the components of the special device with each other. The power of special device comes from the power supply by using a gear.

\section{The Conclusions}

- The efficiency of new cycle is greater than the simple cycle of gas turbine.

- The work ratio of new cycle is lower than the simple cycle of gas turbine.

- The capacity of power plants will be smaller by using the special device, rather than using two or three compressor to increase the efficiency.

- We can make the life more comfortable and economical for persons and factories by decreasing the energy cost.

- We can also decrease the dangerous effects of exhaust gases to the environment by making the fuel consumption more economical.

\section{REFERENCES}

[1] T. D. Eastopand A. McConkey, "Applied Thermodynamic," Longman, Lomdon, 270p. 